\title{
Ultra-high-performance supercritical fluid chromatography with quadrupole-time-of-flight mass spectrometry (UHPSFC/QTOF-MS) for analysis of lignin-derived monomeric compounds in processed lignin samples
}

\author{
Jens Prothmann ${ }^{1} \cdot$ Mingzhe Sun $^{1} \cdot$ Peter Spégel $^{1} \cdot$ Margareta Sandahl $^{1}$. \\ Charlotta Turner ${ }^{1}$
}

Received: 23 June 2017 /Revised: 6 September 2017 / Accepted: 20 September 2017 / Published online: 13 October 2017

(C) The Author(s) 2017. This article is an open access publication

\begin{abstract}
The conversion of lignin to potentially high-value low molecular weight compounds often results in complex mixtures of monomeric and oligomeric compounds. In this study, a method for the quantitative and qualitative analysis of 40 lignin-derived compounds using ultra-high-performance supercritical fluid chromatography coupled to quadrupoletime-of-flight mass spectrometry (UHPSFC/QTOF-MS) has been developed. Seven different columns were explored for maximum selectivity. Makeup solvent composition and ion source settings were optimised using a D-optimal design of experiment (DoE). Differently processed lignin samples were analysed and used for the method validation. The new UHPSFC/QTOF-MS method showed good separation of the 40 compounds within only 6-min retention time, and out of these, 36 showed high ionisation efficiency in negative electrospray ionisation mode.
\end{abstract}

Keywords Column selectivity · Design of experiment · Ionisation efficiency $\cdot$ Lignin $\cdot$ Supercritical fluid chromatography

Jens Prothmann and Mingzhe Sun contributed equally to this work.

Electronic supplementary material The online version of this article (https://doi.org/10.1007/s00216-017-0663-5) contains supplementary material, which is available to authorized users.

Charlotta Turner

charlotta.turner@chem.lu.se

1 Department of Chemistry, Centre for Analysis and Synthesis, Lund University, P.O. Box 124, SE-22100 Lund, Sweden

\section{Introduction}

Lignin is a complex heterogeneous biopolymer containing differently substituted phenylpropanoid units, with the three basic building blocks being $p$-hydroxyphenyl $(\mathrm{H})$, guaiacyl $(G)$ and syringyl (S) [1]. Lignin is also, by far, the most abundant renewable source of aromatic compounds [2]. A necessary process in successful lignin valorisation is the depolymerisation of lignin into low molecular weight units, which can then be further processed into several value-added compounds [2]. Efficient identification and quantification of lignin-derived compounds in complex mixtures is important for the design of an effective lignin valorisation strategy.

Gas chromatography (GC) with flame ionisation detection (FID) and mass spectrometry (MS) detection has, for long, been the dominating technique for monitoring of lignin depolymerisation $[3,4]$. The reasons for this have mainly been the higher resolution, easier coupling with MS and lower costs, compared to LC-based techniques [5]. A disadvantage of GC over LC is the need for a derivatisation step prior to analysis, which will increase the analysis time and also may result in insufficient and discriminative derivatisation that may compromise the quality of the results [6].

In recent years, high-performance LC (HPLC) combined with high-resolution MS (HRMS) has been increasingly applied for the analysis of lignin-derived monomers [7-9]. However, unsatisfying MS sensitivity and in-source fragmentation have been observed with atmospheric pressure ionisation techniques, such as electrospray ionisation (ESI) and atmospheric pressure chemical ionisation (APCI) [9]. The relative ionisation efficiency has been improved for specific lignin products by infusing basic dopants into the mobile phase after the LC column [7-9]. 
Supercritical fluid chromatography (SFC) uses carbon dioxide $\left(\mathrm{CO}_{2}\right)$ in compressed form as the mobile phase. Compared with liquid mobile phases used in HPLC, supercritical $\mathrm{CO}_{2}\left(\mathrm{scCO}_{2}\right)$ has a lower viscosity, allowing for higher flow rates and yielding higher diffusion coefficient for the analytes, which greatly improves the mass transfer [10]. Hence, fast and efficient separation can be achieved by SFC. The resolution in traditional SFC has been further improved by the development of ultra-high-performance supercritical fluid chromatography (UHPSFC) using columns with sub$2-\mu \mathrm{m}$ packing and the development of modern instrument offering lower dispersion [11]. Both polar and non-polar stationary phases can be used with similar mobile phase compositions [11] and the selectivity tuned by altering the column type, column temperature, backpressure and addition of additives $[12,13]$. Compared to GC, SFC has the advantages that no sample derivatisation is needed and the separation can be influenced by altering the mobile phase composition. Currently, SFC has been widely used in the pharmaceutical industry and for analysis of bioactive compounds such as phenolic compounds [14-17]. However, the potential of SFC for analysis of targeted lignin-derived compounds has not yet been comprehensively explored, except for our previous work in which a DAD was used for analysing a relatively small number of lignin-derived compounds [18]. Compared with the HPLC analysis of monomeric lignin model compounds $[7,8,19]$, SFC significantly reduced the analysis time.

Compared to mobile phases used in HPLC, the use of highly volatile supercritical $\mathrm{CO}_{2}$ in UHPSFC may improve the ionisation efficiency in atmospheric pressure ionisation techniques due to an improved desolvation process [20,21]. However, analytes may also precipitate before reaching the ion source when the supercritical $\mathrm{CO}_{2}$ decompresses. The utilisation of an appropriate makeup solvent may reduce this problem, thereby enhancing transfer of analytes into the ion source. Also, the combination of UHPSFC mobile phase $\left(\mathrm{CO}_{2}\right.$ and co-solvent), makeup solvent and makeup solvent additive influences the desolvation and ionisation of analyte ions [20]. To our knowledge, no optimisation of parameters of importance for the ionisation efficiency has been reported for ligninderived monomeric compounds using UHPSFC/MS. GrandGuillaume et al. demonstrated an optimisation of the ionisation efficiency for six pharmaceutical compounds using a UHPSFC/ESI-triple-quadrupole-MS system [22]. Using a design of experiment (DoE) approach, they showed that the mobile phase flow rate and the backpressure have no impact on the ionisation efficiency. However, the makeup solvent flow rate, capillary voltage, desolvation gas temperature and desolvation gas flow rate showed significant effects [22].

In this study, we present, to the best of our knowledge, the first UHPSFC method with HRMS ${ }^{2}$ detection for analysis of lignin-derived monomeric compounds. The selectivities of seven different columns have been studied, along with the influence of makeup solvent compositions and ESI parameters on the ionisation efficiency of a mixture of 40 lignin-derived monomeric compounds. The method has been validated using samples from three different lignin-processing procedures and then finally applied for qualitative and quantitative analysis of four different samples.

\section{Materials and methods}

\section{Chemicals}

Benzoic acid and cinnamic acid were purchased from Mallinckrodt Chemical (Derbyshire UK). The other lignin phenols, as well as ethylvanillin, formic acid, trifluoroacetic acid and ammonium formate, were obtained from Sigma Chemical Co. (St. Louis, MO, USA). Methanol was obtained from Scharlau (Barcelona, Spain). Ethyl acetate and ammonia ( $2 \mathrm{M}$ solution in methanol) were purchased from Fisher Scientific (Waltham, MA, USA). All organic solvents were of LC-MS grade. All water used was from a Milli-Q Water Purification System with a UV unit.

\section{Processed lignin samples}

Three depolymerised kraft lignin (Indulin AT) samples (samples A, B and C) processed under different conditions were kindly provided by Omar Y. Abdelaziz (Lund University, Lund, Sweden). The kraft lignin was depolymerised under base-catalysed conditions using a continuous plug flow reactor. The samples were dissolved in an aqueous solution with $5 \mathrm{wt} \% \mathrm{kraft}$ lignin and $5 \mathrm{wt} \%$ sodium hydroxide. One depolymerised lignin sample (sample D) was kindly provided by Maxim Galking and Joseph Samec (Stockholm University, Stockholm, Sweden).

\section{Sample preparation}

Three millilitres of the processed lignin sample was acidified to $\mathrm{pH} 1$ with $6 \mathrm{~N} \mathrm{HCl}$. Precipitates were removed by centrifugation. The supernatant was collected and extracted three times with $3 \mathrm{~mL}$ of ethyl acetate. The ethyl acetate extracts were combined, and the solvent was evaporated under a flow of $\mathrm{N}_{2}$. Finally, the solid residue was re-dissolved in $2 \mathrm{~mL}$ of methanol.

\section{Preparation of standards}

Single-compound standards with a concentration of $1000 \mu \mathrm{g} / \mathrm{mL}$ were prepared in methanol for guaiacol, eugenol, veratradlehyde, iso-eugenol, syringol, 2,4dimethylphenol, vanillin, acetovanillone, $o$-cresol, $p$-cresol, phenol, syringaldehyde, acetosyringone, coniferyl 
aldehyde, benzoic acid, cinnamic acid, 4-methoxybenzoic acid, sinapaldehyde, 3-methoxycinnamic acid, 4methoxycinnamic acid, 3,5-dimethoxycinnamic acid, $p$ hydroxybenzaldehyde, $p$-hydroxyacetophenone, 3,4dimethoxycinnamic acid, vanillyl alcohol, coniferyl alcohol, vanillic acid, sinapyl alcohol, syringic acid, 2-(4hydroxyphenyl)ethanol, ferulic acid, sinapinic acid, guaiacylglycerol-beta-guaiacyl ether, $p$-hydroxybenzoic acid, $p$-coumaric acid, 3,4-dihydroxyhydrocinnamic acid, 3,4-dihydroxyphenylacetic acid, 3,4-dihydroxybenzoic acid, caffeic acid and 3,5-dihydroxybenzoic acid. Standards were further diluted in methanol to a concentration of $250 \mu \mathrm{g} / \mathrm{mL}$ prior to analysis by UHPSFC/quadrupoletime-of-flight (QTOF)-MS. A multi-standard, including all 40 compounds, was prepared by combining $1 \mathrm{~mL}$ of each standard followed by evaporation of the solvent under a flow of $\mathrm{N}_{2}$. Finally, the dry residue was re-dissolved in $4 \mathrm{~mL}$ of methanol to give a final concentration of each compound of $250 \mu \mathrm{g} / \mathrm{mL}$.

\section{Equipment}

Chromatographic separation was performed with a Waters Ultra Performance Convergence Chromatography System (Waters, Milford, MA, USA) with a diode array detector (ACQUITY UPC ${ }^{2}$ PDA detector, Waters). The UHPSFC/ DAD system was also hyphenated via a flow splitter (ACQUITY UPC ${ }^{2}$ splitter, Waters) with a Waters XEVO-G2 QTOF-MS (Waters).

\section{Software}

Instruments were controlled and data acquired using Waters MassLynx 4.1 software. Modde ${ }^{\mathrm{TM}}$ 10.1.0 (Umetrics, Umeå, Sweden) was used for creation and evaluation of experimental designs. The open-source software MZmine 2 was used for data evaluation.

\section{Column and mobile phase additive screening}

Seven columns were screened for the separation of the standards on the UHPSFC/DAD: Waters Torus 1-AA (1-aminoanthrocene, $1.7 \mu \mathrm{m}, 3 \mathrm{~mm} \times 100 \mathrm{~mm}$ ), Torus DIOL $(1.7 \mu \mathrm{m}, 3 \mathrm{~mm} \times 100 \mathrm{~mm})$, Torus DEA (diethylamine, $1.7 \mu \mathrm{m}, 3 \mathrm{~mm} \times 100 \mathrm{~mm}$ ), Torus 2-PIC (2-picolylamine, $1.7 \mu \mathrm{m}, 3 \mathrm{~mm} \times 100 \mathrm{~mm}$ ), ACQUITY UPC $^{2}$ HSS C18 SB $(1.8 \mu \mathrm{m}, 3 \mathrm{~mm} \times 100 \mathrm{~mm})$, ACQUITY UPC $^{2}$ CSH FP (fluorophenyl, $1.7 \mu \mathrm{m}, 3 \mathrm{~mm} \times 100 \mathrm{~mm}$ ) and ACQUITY $\mathrm{UPC}^{2} \mathrm{BEH}$ (ethylene-bridged silica, $1.7 \mu \mathrm{m}, 3 \mathrm{~mm} \times 100 \mathrm{~mm}$ ). The mobile phase consisted of $\mathrm{scCO}_{2}$ with methanol as a co-solvent. To improve the peak shape of the relatively more polar phenolic acid analytes, formic acid and ammonium formate were explored as mobile phase additives. In order to compare the selectivity of the columns, similar retention times of the compound test mixture were achieved by using different binary gradient elution programs with solvent $\mathrm{A}$ being $\mathrm{CO}_{2}$ and solvent $\mathrm{B}$ being methanol or methanol with different concentrations of additives. The mobile phase gradient for 1-AA and DIOL columns started at $1.0 \% \mathrm{~B}$ (vol.\%), where it was held for $0.5 \mathrm{~min}$ and then ramped up to $20 \% \mathrm{~B}$ (vol.\%) for $5 \mathrm{~min}$, then held for $2 \mathrm{~min}$ and then returning to starting condition in $1 \mathrm{~min}$. The gradient for the 2-PIC column started with $1.0 \% \mathrm{~B}$ (vol.\%), held for $0.5 \mathrm{~min}$ and then ramped up to $35 \% \mathrm{~B}$ (vol.\%) until $6 \mathrm{~min}$, then held for $2 \mathrm{~min}$ and decreasing to starting composition in $0.5 \mathrm{~min}$. The mobile phase gradient for the DEA column started with $1.0 \% \mathrm{~B}$ (vol.\%), held for $0.5 \mathrm{~min}$ and then ramped up to $35 \%$ B (vol.\%) until $4.5 \mathrm{~min}$, then held for $13.5 \mathrm{~min}$ and decreasing to starting composition in $1 \mathrm{~min}$. The mobile phase gradient for the BEH column started with 1.0\% B (vol.\%), held for $0.5 \mathrm{~min}$ and then ramped up to $10 \% \mathrm{~B}$ (vol. \%) until $5 \mathrm{~min}$, then held for $2 \mathrm{~min}$ and decreasing to starting composition in $1 \mathrm{~min}$. The mobile phase gradient for the $\mathrm{C} 18$ and FP columns started with $1.0 \% \mathrm{~B}$ (vol.\%), held for $3 \mathrm{~min}$ and then ramped up to $10 \% \mathrm{~B}$ (vol. \%) until $6 \mathrm{~min}$, then held for $1 \mathrm{~min}$ and decreasing to starting composition in $1 \mathrm{~min}$. The flow rate was $2.0 \mathrm{~mL} / \mathrm{min}$, the column temperature was $45{ }^{\circ} \mathrm{C}$ and the backpressure was 125 bar for all columns. The injection volume was $1.5 \mu \mathrm{L}$. The columns were flushed and stored in $\mathrm{CO}_{2}$ when not in use. The DAD was collecting data at $20 \mathrm{~Hz}$, the filter time was $0.1 \mathrm{~s}$ and spectra from 250 to $500 \mathrm{~nm}$ were collected with a resolution of $1.2 \mathrm{~nm}$. Signal data was collected at $280 \mathrm{~nm}$.

\section{Chromatographic parameters tuning}

The DIOL column was chosen for tuning of the chromatographic parameters, as it provided the best overall resolution in a relatively short analysis time. The mobile phase flow rate was varied between 1.5 and $2.5 \mathrm{~mL} / \mathrm{min}$, the column temperature was altered between 40 and $60{ }^{\circ} \mathrm{C}$ and the backpressure was varied between 110 and 155 bar. Formic acid and ammonium formate were tested as mobile phase additives at different concentrations. One parameter was changed at a time, keeping all other parameters constant (flow rate $2.0 \mathrm{~mL} / \mathrm{min}$; column temperature $45^{\circ} \mathrm{C}$; backpressure 125 bar; no mobile phase additive).

The final optimised UHPSFC method used the DIOL column at $50{ }^{\circ} \mathrm{C}$ as the column temperature and 130 bar as the final backpressure. The elution gradient started with $0 \% \mathrm{~B}$ (vol.\%) and then ramped up to $8.5 \% \mathrm{~B}$ (vol.\%) until $2.5 \mathrm{~min}$, then ramped up to $25 \% \mathrm{~B}$ (vol.\%) until $5.5 \mathrm{~min}$, then held for $2 \mathrm{~min}$ and decreasing to starting composition in $0.5 \mathrm{~min}$, with $\mathrm{A}$ being $\mathrm{CO}_{2}$ and $\mathrm{B}$ being methanol. The flow rate was set to $2.0 \mathrm{~mL} / \mathrm{min}$, and the injection volume was $1.5 \mu \mathrm{L}$. 
Table 1 Overview of the qualitative and quantitative variables for the created design of experiment (D-optimal design) for the optimisation of the MS ionisation efficiency of a mixture of 40 lignin-derived monomeric compounds

\begin{tabular}{lllll}
\hline & Variable settings & \multicolumn{2}{l}{ Variable ranges } \\
\cline { 3 - 5 } & & -1 & 0 & +1 \\
\hline Qualitative variables & & & \\
Makeup solvents & Methanol, isopropanol & & \\
Makeup solvent additives & Formic acid, ammonium & & \\
Quantitative variables & formate, ammonia & & \\
Makeup solvent flow rate $(\mathrm{mL} / \mathrm{min})$ & & 0.2 & 0.5 & 0.8 \\
Concentration of makeup solvent additive $(\mathrm{mmol} / \mathrm{L})$ & & 5 & 10 & 15 \\
ESI source temperature $\left({ }^{\circ} \mathrm{C}\right)$ & & 120 & 135 & 150 \\
ESI source desolvation gas temperature $\left({ }^{\circ} \mathrm{C}\right)$ & & 300 & 450 & 600 \\
ESI source desolvation gas flow $(\mathrm{L} / \mathrm{h})$ & 800 & 1000 & 1200 \\
ESI source capillary voltage $(\mathrm{kV})$ & & 2.0 & 2.5 & 3.0 \\
ESI source cone voltage $(\mathrm{V})$ & 20 & 35 & 50 \\
\hline
\end{tabular}

\section{Optimisation of mass spectrometer settings}

An interaction model with a D-optimal design was used to optimise the MS parameters, using the number of detected peaks in the multi-standard with a relative base peak intensity in negative ionisation mode equal or higher than $1.0 E 5$ as a response. The lower limit was set to ensure that a good $\mathrm{MS}^{2}$ spectrum could be obtained. Peak detection (using MZmine) was based on exact masses and retention times of the standards. A minimum MS intensity of $1.0 E 5$, an $\mathrm{m} / \mathrm{z}$ range of $\pm 0.005 \mathrm{Da}$ and a retention time range of \pm 0.05 min were used. A match for exact mass, retention time and $\mathrm{MS}^{2}$ spectrum was required for positive identification. Multiple linear regression (MLR) was used to evaluate the D-optimal design. To reduce noise in the model, it was optimised by stepwise removing of insignificant variables and variable interactions until the best cross-validated predictability $\left(Q^{2} Y\right)$ was reached.

In the D-optimal design, two qualitative and seven quantitative variables were investigated. The two qualitative variables were the type of makeup solvent, methanol or isopropanol, and the type of makeup solvent additive, formic acid, ammonium formate or ammonia (Table 1). To dissolve the ammonium formate, the isopropanol was mixed with $20 \%$ methanol. The quantitative variables, makeup solvent flow rate and additive concentration, ESI source temperature, desolvation gas temperature and flow, capillary and cone voltages, were varied as outlined in Table 1 . The design included 66 runs with three centre points. The tested values of each experiment are shown in Table S1 (see the Electronic Supplementary Material (ESM)). Analyses were performed in negative ionisation mode, with a cone gas flow of $40 \mathrm{~L} / \mathrm{h}$ and an extractor cone voltage of $4 \mathrm{~V}$. The scan time was set to $0.1 \mathrm{~s}$ with a scan range of $m / z, 50-1000$. For the optimisation of the MS ionisation efficiency, a previously developed UHPSFC method with the following conditions was used: a BEH 2-EP column $(1.7 \mu \mathrm{m}, 3 \mathrm{~mm} \times 100 \mathrm{~mm})$ was used with a column temperature of $45^{\circ} \mathrm{C}$ and a backpressure of 125 bar. The elution gradient started with $1 \% \mathrm{~B}$ (vol.\%), where it was held for $1 \mathrm{~min}$, followed by a ramp up to 25 $\%$ B (vol. \%) until $9 \mathrm{~min}$, where it was held for $1 \mathrm{~min}$, after which it returned to starting composition in $1 \mathrm{~min}$, with $\mathrm{A}$ being $\mathrm{CO}_{2}$ and $\mathrm{B}$ methanol. The flow rate was set at $1.0 \mathrm{~mL} / \mathrm{min}$. As injection solvent, methanol was used. The injection volume was set to $1.5 \mu \mathrm{L}$.

The best QTOF-MS settings were as follows: methanol as a makeup solvent, $5 \mathrm{mmol} / \mathrm{L}$ ammonia as a makeup solvent additive, a makeup solvent flow rate of $0.2 \mathrm{~mL} / \mathrm{min}$, a source temperature of $120{ }^{\circ} \mathrm{C}$, a desolvation gas temperature of $600{ }^{\circ} \mathrm{C}$, a desolvation gas flow of $1200 \mathrm{~L} / \mathrm{h}$, a capillary voltage of $3.0 \mathrm{kV}$ and a source cone voltage of $20 \mathrm{~V}$.

\section{Tandem mass spectrometry experiments}

$\mathrm{MS}^{2}$ data were collected for each of the standard compounds using the final optimised UHPSFC method combined with the best QTOF-MS settings. A collision-induced dissociation (CID) energy ramp from 20 to $35 \mathrm{~V}$ was used.

\section{Method validation}

Spiked processed lignin samples were employed for method validation. One phenolic aldehyde (syringaldehyde), one acid (3,4-dimethoxycinnamic acid) and one alcohol (sinapyl alcohol) were spiked into samples A, B, C and $\mathrm{D}$ at 12 different concentrations $(0.1,0.2,1.0,2.0,10,20$, $100,200,1000,2000,3000$ and $5000 \mu \mathrm{g} / \mathrm{mL})$ to 

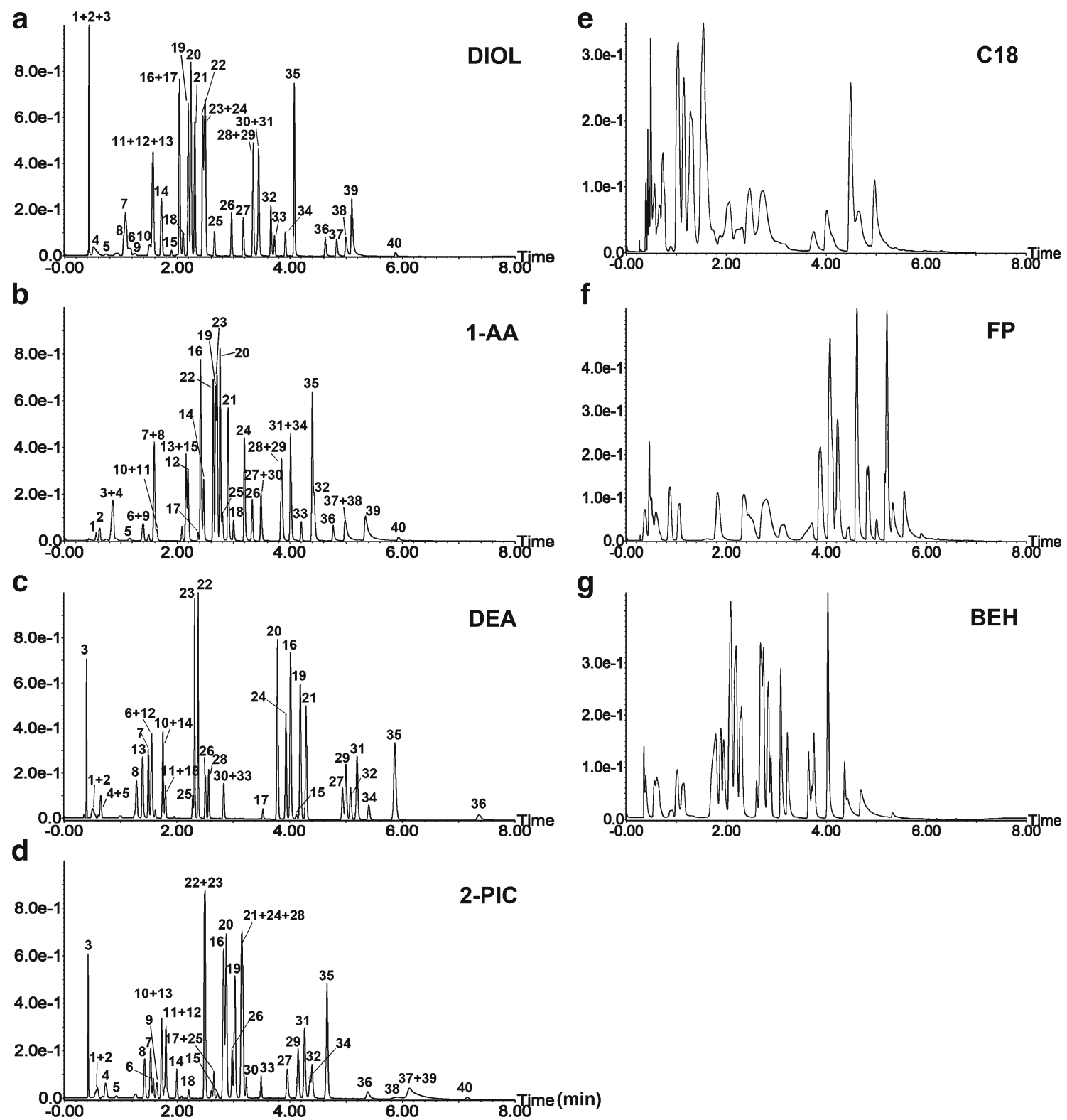

Fig. 1 UHPSFC-DAD chromatograms and elution orders of 40 lignin-derived compounds on seven different columns: (a) DIOL, (b) 1-AA, (c) DEA, (d) 2-PIC, (e) C18, (f) FP and (g) BEH. For SFC conditions for different columns, see the "Materials and methods" part. For peak identities, see Table 2

determine the linear dynamic range, limits of detection (LOD) and limits of quantification (LOQ). LOD and LOQ were determined at 3 and 10 times signal-to-noise $(\mathrm{S} / \mathrm{N})$ ratio, respectively. Calibration curves for quantitative determination of the three compounds were also drawn based on the results within the dynamic range. The repeatability of the method was examined with six consecutive injections of two spiked samples: one spiked at concentrations near the respective LOQ and the other near the centre of the calibration curve. The reproducibility of the method was examined with injections of the same spiked sample on three non-consecutive days. The recoveries of chromatographic analysis of the three compounds were estimated with the ratio between the slope of the spiked sample calibration curve and that of the calibration curve obtained from injection of standard mixture in the same concentration range.

\section{Results and discussion}

We have previously shown that $\mathrm{SFC}$ is a promising technique for the analysis of lignin-derived compounds [18]. Now, we are extending this approach to a broader range of phenolics by exploiting seven different SFC columns with modern stationary phase technology and HRMS detection. A DoE approach 


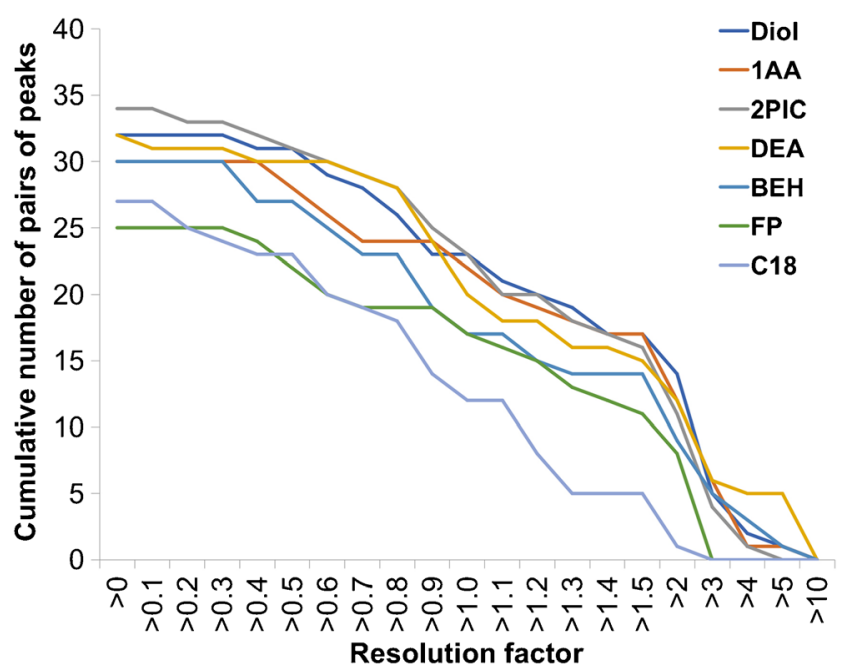

Fig. 2 Resolution-level graph for column screening. Different coloured lines represent different columns

was used to optimise the ionisation processes, and the optimised method was validated and applied for the analysis of processed lignin products.

\section{Column screening}

As shown in Fig. 1, DIOL, 1-AA, DEA and 2-PIC columns exhibited better resolution than the other three columns: C18, FP and BEH (Fig. 1). The overall resolution achieved for the screened columns is visualised in a resolution-level graph that shows the cumulative number of peaks at resolutions larger than the stated values on the $X$-axis (Fig. 2). The $X$-axis shows a series of different resolution factor levels, while the cumulative number of peaks with a resolution factor qualified for each level is on the $Y$-axis. The graph shows the advantage of DIOL, 1-AA, 2-PIC and DEA columns in terms of both the number of peaks partially separated $(0<\mathrm{Rs}<1.5)$ and the number of peaks showing baseline separation (Rs $>1.5$ ). The resolving power of these four columns can be attributed to the latest stationary-phase bonding technology and how the chromatographic particles are functionalised. The 1-AA column is the only column among the four that retained and provided reasonable separation of guaiacol, eugenol and veratraldehyde. This is probably due to the enhanced $\pi-\pi$ interactions with the analytes offered by the three benzene rings. Hence, this column can resolve compounds differing in the number of double bonds, for example guaiacol and eugenol (Fig. 1, peaks 1 and 2). Apparent is also the relatively stronger affinity towards guaiacylglycerol-beta-guaiacyl (Fig. 1, peak 33), the only dimeric compound in the mixture, in comparison to the 2PIC and DEA columns. The dimer was eluted as the $33 \mathrm{rd}$ peak, compared to the 22nd peak with DEA and the 28th peak with 2-PIC. However, the 1-AA column provides

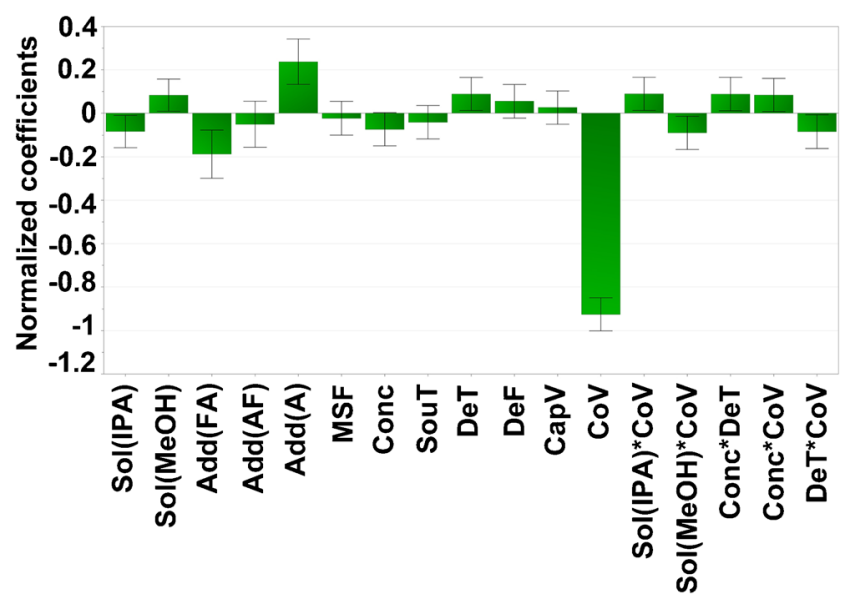

Fig. 3 Normalised influence of investigated variables on the number of detected peaks with a base peak intensity $\geq 1.0 E 5$. Sol solvent, Add additive, IPA isopropanol, $\mathrm{MeOH}$ methanol, FA formic acid, AF ammonium formate, A ammonia, MSF makeup solvent flow rate, Conc concentration of makeup solvent additive, SouT ion source temperature, DeT desolvation gas temperature, DeF desolvation gas flow, CapV capillary voltage, $\mathrm{CoV}$ cone voltage

generally low selectivity for the number of methyl substitutions, as indicated by the co-elution of 2,4dimethylphenol (Fig. 1, peaks 6 and 9) and $o$-cresol; vanillin and acetovanillone (Fig. 1, peaks 7 and 8); and phenol and $p$-cresol (Fig. 1, peaks 10 and 11).

The high-density DIOL column showed a hydrogen bonding-based separation mechanism. The elution order was largely controlled by the number of hydroxyl and carboxylate groups on the analytes. The dimeric compound guaiacylglycerol-beta-guaiacyl which has three hydroxyl groups showed a strong retention on the DIOL column similarly as with the 1-AA column (eluted as the 33rd peak). Also, the position of the hydroxyl group on the benzene ring contributed to the separation as it decides the availabilities of the hydroxyl groups for interactions.

The 2-PIC column offered some retention of guaiacol and eugenol (Fig. 1, peaks 1 and 2) but failed to separate these two due to relatively weaker $\pi-\pi$ interactions with the analytes compared with the 1-aminoanthrocene column. However, the retention of phenolic acids was stronger. The three most retained acids for both columns were caffeic acid, 3,5-dihydroxybenzoic acid and 3,4dihydroxyphenylacetic acid. They all had higher retention factors on the 2-PIC column than on the 1-AA column (16.57 compared to 13.23 for 3,4-dihydroxyphenylacetic acid; 16.57 compared to 14.26 for caffeic acid; 19.16 compared to 15.89 for 3,5-dihydroxybenzoic acid). The reason could be that the pyridyl functional group is positively charged which has ion-dipole interaction with the acidic compounds.

The most acidic compounds in the standard mixture, 3,4dihydroxybenzoic acid, caffeic acid, 3,5-dihydroxybenzoic 
Table 2 Measured retention times, calculated and measured $\mathrm{m} / \mathrm{z}$ values, base peak intensities and obtained $\mathrm{MS}^{2}$ fragments of the 40 lignin-derived monomeric compounds in the multi-standard. $\mathrm{MS}^{2}$ fragments are evaluated from single-standard runs

\begin{tabular}{|c|c|c|c|c|c|c|c|}
\hline \multirow{2}{*}{$\begin{array}{l}\text { Peak } \\
\text { number }\end{array}$} & \multirow[t]{2}{*}{ Compound } & \multirow{2}{*}{$\begin{array}{l}\text { Retention } \\
\text { time (min) }\end{array}$} & \multirow{2}{*}{$\begin{array}{l}\text { Calculated } \\
m / z\left([\mathrm{M}-\mathrm{H}]^{-}\right)\end{array}$} & \multirow{2}{*}{$\begin{array}{l}\text { Measured } \\
m / z\left([\mathrm{M}-\mathrm{H}]^{-}\right)\end{array}$} & \multirow{2}{*}{$\begin{array}{l}\text { Base peak } \\
\text { intensity }\end{array}$} & \multicolumn{2}{|c|}{$\mathrm{MS}^{2}$ fragmentation } \\
\hline & & & & & & $\begin{array}{l}\mathrm{MS}^{2} \\
\text { transition }\end{array}$ & Lost fragment \\
\hline 1 & Guaiacol & 0.48 & 123.0446 & 123.0440 & $1.4 E 5$ & $\begin{array}{l}123 \rightarrow 108 \\
123 \rightarrow 75\end{array}$ & $\begin{array}{l}\mathrm{CH}_{3} \\
\mathrm{H}_{2} \mathrm{O}+\mathrm{OCH}_{2}\end{array}$ \\
\hline 2 & Eugenol & 0.48 & 163.0759 & 163.0755 & $6.0 E 5$ & $\begin{aligned} & 163 \rightarrow 149 \\
& 163 \rightarrow 148 \\
& 163 \rightarrow 121\end{aligned}$ & $\begin{array}{l}\mathrm{CH}_{2} \\
\mathrm{CH}_{2}+\mathrm{CH}_{3} \\
\mathrm{C}_{2} \mathrm{H}_{3}+\mathrm{CH}_{3}\end{array}$ \\
\hline 3 & Veratraldehyde & $0.48^{\mathrm{a}}$ & 165.0552 & - & - & - & - \\
\hline 4 & Iso-eugenol & 0.67 & 163.0759 & 163.0757 & $9.6 E 4$ & $\begin{aligned} & 163 \rightarrow 149 \\
& 163 \rightarrow 148 \\
& 163 \rightarrow 121\end{aligned}$ & $\begin{array}{l}\mathrm{CH}_{2} \\
\mathrm{CH}_{2}+\mathrm{CH}_{3} \\
\mathrm{C}_{2} \mathrm{H}_{3}+\mathrm{CH}_{3}\end{array}$ \\
\hline 5 & Syringol & 1.02 & 153.0552 & 153.0546 & $1.6 E 5$ & $\begin{array}{l}153 \rightarrow 123 \\
153 \rightarrow 95\end{array}$ & $\begin{array}{l}2 \times \mathrm{CH}_{3} \\
2 \times \mathrm{CH}_{3}+\mathrm{CO}\end{array}$ \\
\hline 6 & 2,4-Dimethylphenol & 1.23 & 121.0654 & 121.0648 & $2.6 E 5$ & - & - \\
\hline 7 & Vanillin & 1.26 & 151.0395 & 151.0391 & $2.1 E 6$ & $\begin{array}{l}151 \rightarrow 136 \\
151 \rightarrow 108 \\
151 \rightarrow 92\end{array}$ & $\begin{array}{l}\mathrm{CH}_{3} \\
\mathrm{CH}_{3}+\mathrm{CO} \\
\mathrm{CH}_{3}+\mathrm{CO}+\mathrm{O}\end{array}$ \\
\hline 8 & Acetovanillone & 1.26 & 165.0552 & 165.0543 & $2.0 E 6$ & $\begin{array}{l}165 \rightarrow 150 \\
165 \rightarrow 122\end{array}$ & $\begin{array}{l}\mathrm{CH}_{3} \\
\mathrm{CH}_{3}+\mathrm{CO}\end{array}$ \\
\hline 9 & $o$-Cresol & 1.29 & 107.0497 & 107.0492 & $1.5 E 5$ & - & - \\
\hline 10 & $p$-Cresol & 1.50 & 107.0497 & 107.0493 & $1.3 E 5$ & $\begin{array}{l}107 \rightarrow 91 \\
107 \rightarrow 75\end{array}$ & $\begin{array}{l}\mathrm{O} \\
\mathrm{OH}+\mathrm{CH}_{3}\end{array}$ \\
\hline 11 & Phenol & 1.56 & 93.0341 & 93.0340 & $3.2 E 4$ & - & - \\
\hline 12 & Syringaldehyde & 1.64 & 181.0501 & 181.0498 & $2.3 E 6$ & $\begin{aligned} & 181 \rightarrow 166 \\
& 181 \rightarrow 151 \\
& 181 \rightarrow 123\end{aligned}$ & $\begin{array}{l}\mathrm{CH}_{3} \\
\mathrm{OCH}_{2} \\
2 \times \mathrm{CH}_{3}+\mathrm{CO}\end{array}$ \\
\hline 13 & Acetosyringone & 1.63 & 195.0658 & 195.0652 & $1.6 E 6$ & $\begin{aligned} 195 & \rightarrow 180 \\
195 & \rightarrow 165 \\
195 & \rightarrow 137\end{aligned}$ & $\begin{array}{l}\mathrm{CH}_{3} \\
2 \times \mathrm{CH}_{3} \\
2 \times \mathrm{CH}_{3}+\mathrm{CO}\end{array}$ \\
\hline 14 & Coniferyl aldehyde & 1.77 & 177.0552 & 177.0545 & $4.1 E 6$ & $\begin{array}{l}177 \rightarrow 162 \\
177 \rightarrow 134\end{array}$ & $\begin{array}{l}\mathrm{CH}_{3} \\
\mathrm{CH}_{3}+\mathrm{CO}\end{array}$ \\
\hline 15 & Benzoic acid & 1.89 & 121.0290 & 121.0287 & $3.8 E 5$ & $121 \rightarrow 77^{\mathrm{b}}$ & $\mathrm{CO}_{2}$ \\
\hline 16 & Cinnamic acid & 2.04 & 147.0446 & 147.0446 & $2.3 E 6$ & $\begin{array}{l}147 \rightarrow 103 \\
147 \rightarrow 77\end{array}$ & $\begin{array}{l}\mathrm{CO}_{2} \\
\mathrm{C}_{2} \mathrm{H}_{2} \mathrm{CO}_{2}\end{array}$ \\
\hline 17 & 4-Methoxybenzoic acid & 2.06 & 151.0395 & 151.0393 & $8.1 E 6$ & $\begin{array}{l}151 \rightarrow 107 \\
151 \rightarrow 92\end{array}$ & $\begin{array}{l}\mathrm{CO}_{2} \\
\mathrm{CO}_{2}+\mathrm{CH}_{3}\end{array}$ \\
\hline 18 & Sinapaldehyde & 2.14 & 207.0658 & 207.0654 & $3.4 E 6$ & $\begin{array}{l}207 \rightarrow 177 \\
207 \rightarrow 149\end{array}$ & $\begin{array}{l}2 \times \mathrm{CH}_{3} \\
2 \times \mathrm{CH}_{3}+\mathrm{CO}\end{array}$ \\
\hline 19 & 3-Methoxycinnamic acid & 2.22 & 177.0552 & 177.0548 & $3.6 E 6$ & $\begin{aligned} 177 & \rightarrow 133 \\
177 & \rightarrow 103\end{aligned}$ & $\begin{array}{l}\mathrm{CO}_{2} \\
\mathrm{OCH}_{2}+\mathrm{CO}_{2}\end{array}$ \\
\hline 20 & 4-Methoxycinnamic acid & 2.27 & 177.0552 & 177.0547 & $2.8 E 6$ & $\begin{aligned} 177 & \rightarrow 133 \\
177 & \rightarrow 117\end{aligned}$ & $\begin{array}{l}\mathrm{CO}_{2} \\
\mathrm{C}_{2} \mathrm{H}_{2} \mathrm{CO}_{2}\end{array}$ \\
\hline 21 & 3,5-Dimethoxycinnamic acid & 2.36 & 207.0658 & 207.0655 & $3.5 E 6$ & $\begin{array}{l}207 \rightarrow 133 \\
207 \rightarrow 118\end{array}$ & $\begin{array}{l}\mathrm{CO}_{2}+\mathrm{CH}_{2} \mathrm{O} \\
\mathrm{CO}_{2}+\mathrm{CH}_{3}+\mathrm{CH}_{2} \mathrm{O}\end{array}$ \\
\hline 22 & $p$-Hydroxybenzaldehyde & 2.50 & 121.0290 & 121.0287 & $3.5 E 6$ & $121 \rightarrow 92$ & $\mathrm{CHO}$ \\
\hline 23 & $p$-Hydroxyacetophenone & 2.54 & 135.0446 & 135.0441 & $4.0 E 6$ & $\begin{array}{l}135 \rightarrow 120 \\
135 \rightarrow 92\end{array}$ & $\begin{array}{l}\mathrm{CH}_{3} \\
\mathrm{C}_{2} \mathrm{H}_{3} \mathrm{O}\end{array}$ \\
\hline 24 & 3,4-Dimethoxycinnamic acid & 2.57 & 207.0658 & 207.0650 & $3.0 E 6$ & $207 \rightarrow 103$ & $\mathrm{CO}_{2}+2 \times \mathrm{CH}_{2} \mathrm{O}$ \\
\hline 25 & Vanillyl alcohol & 2.69 & 153.0552 & 153.0550 & $8.2 E 5$ & $\begin{array}{l}153 \rightarrow 135 \\
153 \rightarrow 120\end{array}$ & $\begin{array}{l}\mathrm{H}_{2} \mathrm{O} \\
\mathrm{H}_{2} \mathrm{O}+\mathrm{CH}_{3}\end{array}$ \\
\hline 26 & Coniferyl alcohol & 3.03 & 179.0708 & 179.0705 & $2.0 E 6$ & $\begin{aligned} 179 & \rightarrow 164 \\
179 & \rightarrow 146\end{aligned}$ & $\begin{array}{l}\mathrm{CH}_{3} \\
\mathrm{CH}_{3}+\mathrm{H}_{2} \mathrm{O}\end{array}$ \\
\hline 27 & Vanillic acid & 3.28 & 167.0345 & 167.0336 & $2.9 E 6$ & $167 \rightarrow 152$ & $\mathrm{CH}_{3}$ \\
\hline
\end{tabular}


Table 2 (continued)

\begin{tabular}{|c|c|c|c|c|c|c|c|}
\hline \multirow{2}{*}{$\begin{array}{l}\text { Peak } \\
\text { number }\end{array}$} & \multirow[t]{2}{*}{ Compound } & \multirow{2}{*}{$\begin{array}{l}\text { Retention } \\
\text { time (min) }\end{array}$} & \multirow{2}{*}{$\begin{array}{l}\text { Calculated } \\
m / z\left([\mathrm{M}-\mathrm{H}]^{-}\right)\end{array}$} & \multirow{2}{*}{$\begin{array}{l}\text { Measured } \\
m / z\left([\mathrm{M}-\mathrm{H}]^{-}\right)\end{array}$} & \multirow{2}{*}{$\begin{array}{l}\text { Base peak } \\
\text { intensity }\end{array}$} & \multicolumn{2}{|c|}{$\mathrm{MS}^{2}$ fragmentation } \\
\hline & & & & & & $\begin{array}{l}\mathrm{MS}^{2} \\
\text { transition }\end{array}$ & Lost fragment \\
\hline & & & & & & $\begin{array}{l}167 \rightarrow 123 \\
167 \rightarrow 108\end{array}$ & $\begin{array}{l}\mathrm{CO}_{2} \\
\mathrm{CH}_{3}+\mathrm{CO}_{2}\end{array}$ \\
\hline 28 & Sinapyl alcohol & 3.46 & 209.0814 & 209.0808 & $1.2 E 6$ & $\begin{aligned} 209 & \rightarrow 179 \\
209 & \rightarrow 161 \\
209 & \rightarrow 151\end{aligned}$ & $\begin{array}{l}2 \times \mathrm{CH}_{3} \\
2 \times \mathrm{CH}_{3}+\mathrm{H}_{2} \mathrm{O} \\
2 \times \mathrm{CH}_{3}+\mathrm{CO}\end{array}$ \\
\hline 29 & Syringic acid & 3.50 & 197.0450 & 197.0446 & $3.4 E 6$ & $\begin{aligned} 197 & \rightarrow 167 \\
197 & \rightarrow 123 \\
197 & \rightarrow 95\end{aligned}$ & $\begin{array}{l}2 \times \mathrm{CH}_{3} \\
2 \times \mathrm{CH}_{3}+\mathrm{CO}_{2} \\
2 \times \mathrm{CH}_{3}+\mathrm{CO}_{2}+\mathrm{CO}\end{array}$ \\
\hline 30 & 2-(4-Hydroxyphenyl)ethanol & 3.55 & 137.0603 & 137.0594 & $2.9 E 6$ & $\begin{aligned} 137 & \rightarrow 119 \\
137 & \rightarrow 106\end{aligned}$ & $\begin{array}{l}\mathrm{H}_{2} \mathrm{O} \\
\mathrm{CH}_{2} \mathrm{OH}\end{array}$ \\
\hline 31 & Ferulic acid & 3.58 & 193.0501 & 193.0497 & $3.7 E 6$ & $193 \rightarrow 134$ & $\mathrm{CH}_{3}+\mathrm{CO}_{2}$ \\
\hline 32 & Sinapinic acid & 3.81 & 223.0607 & 223.0603 & $3.7 E 6$ & $\begin{array}{l}223 \rightarrow 193 \\
223 \rightarrow 149 \\
223 \rightarrow 121\end{array}$ & $\begin{array}{l}2 \times \mathrm{CH}_{3} \\
2 \times \mathrm{CH}_{3}+\mathrm{CO}_{2} \\
2 \times \mathrm{CH}_{3}+\mathrm{CO}_{2} \\
+2 \times \mathrm{CH}_{2}\end{array}$ \\
\hline 33 & Guaiacylglycerol-beta-guaiacyl ether & 3.87 & 319.1182 & 319.1174 & $5.9 E 5$ & $\begin{array}{l}319 \rightarrow 256 \\
319 \rightarrow 149\end{array}$ & $\begin{array}{l}\mathrm{CH}_{2} \mathrm{O}+\mathrm{H}_{2} \mathrm{O}+\mathrm{CH}_{3} \\
\mathrm{CH}_{2} \mathrm{O}+\mathrm{H}_{2} \mathrm{O}+\mathrm{CH}_{3}+\mathrm{C}_{6} \mathrm{H}_{3} \mathrm{O}_{2}\end{array}$ \\
\hline 34 & $p$-Hydroxybenzoic acid & 4.05 & 137.0239 & 137.0245 & $3.0 E 6$ & $137 \rightarrow 93$ & $\mathrm{CO}_{2}$ \\
\hline 35 & $p$-Coumaric acid & 4.19 & 163.0395 & 163.0390 & $3.8 E 6$ & $\begin{array}{l}163 \rightarrow 119 \\
163 \rightarrow 93\end{array}$ & $\begin{array}{l}\mathrm{CO}_{2} \\
\mathrm{C}_{2} \mathrm{H}_{2} \mathrm{CO}_{2}\end{array}$ \\
\hline 36 & 3,4-Dihydroxyhydrocinnamic acid & 4.66 & 181.0501 & 181.0492 & $3.6 E 6$ & $181 \rightarrow 137$ & $\mathrm{CO}_{2}$ \\
\hline 37 & 3,4-Dihydroxyphenylacetic acid & 4.84 & 167.0345 & 167.0345 & $9.0 E 4$ & $167 \rightarrow 123$ & $\mathrm{CO}_{2}$ \\
\hline 38 & 3,4-Dihydroxybenzoic acid & 4.98 & 153.0188 & 153.0177 & $2.3 E 6$ & $153 \rightarrow 109$ & $\mathrm{CO}_{2}$ \\
\hline 39 & Caffeic acid & 5.07 & 179.0345 & 179.0342 & $2.7 E 6$ & $179 \rightarrow 135$ & $\mathrm{CO}_{2}$ \\
\hline 40 & 3,5-Dihydroxybenzoic acid & 5.66 & 153.0188 & 153.0186 & $2.9 E 6$ & $153 \rightarrow 109$ & $\mathrm{CO}_{2}$ \\
\hline
\end{tabular}

${ }^{a}$ Retention time from UV detection

${ }^{\mathrm{b}}$ Fragment seen in $\mathrm{MS}^{1}$ spectrum

acid and 3,4-dihydroxyphenylacetic acid (see ESM Fig. S1, peaks $38,39,40$ and 37), showed very strong retention on the DEA column $(k=24.80,28.03,28.03$ and 32.00, respectively). In fact, they could only be eluted by maintaining a high percentage of methanol in the mobile phase (35 vol.\%) for a relatively long time at the end of the gradient. This feature of the column could be attributed to protonated tertiary amines on the stationary phase, resulting in strong ion-dipole interactions with phenolic acids.

The DIOL column was finally selected because of the good general resolution, relatively short analysis time, good peak shapes of acidic compounds and a comparatively lower consumption of co-solvent.

\section{Tuning of chromatographic parameters}

In an attempt to further improve the peak shape of lateeluting peaks on the DIOL column, formic acid and ammonium formate were tested as co-solvent additives at two different concentrations (10 and $50 \mathrm{mM}$ ). Formic acid did not improve peak shapes of the late-eluting phenolic acids, while the addition of ammonium formate rather had negative effects (ESM Fig. S2). Although the elution profile was changed with the addition of the additives, no improvement of the overall separation was observed. Interestingly, the addition of formic acid and ammonium formate had opposite impact on retention of the more polar compounds. A possible explanation for this could be that formic acid not only lowers the apparent $\mathrm{pH}$ of the mobile phase and eliminates the ionisation of the analytes but also competes with the analytes for binding to the nonendcapped silica sites, resulting in lower retention of the analytes $[23,24]$. The addition of ammonium formate might help to stabilise the apparent $\mathrm{pH}$ of the mobile phase, which might cause some acidic compounds to be in ionised form. Additionally, ammonium formate adsorbed on the stationary surface and in the layer covering the stationary phase with higher co-solvent concentration than the bulk mobile phase can increase acidic analyte adsorption on the stationary phase through ion pairing [25]. 


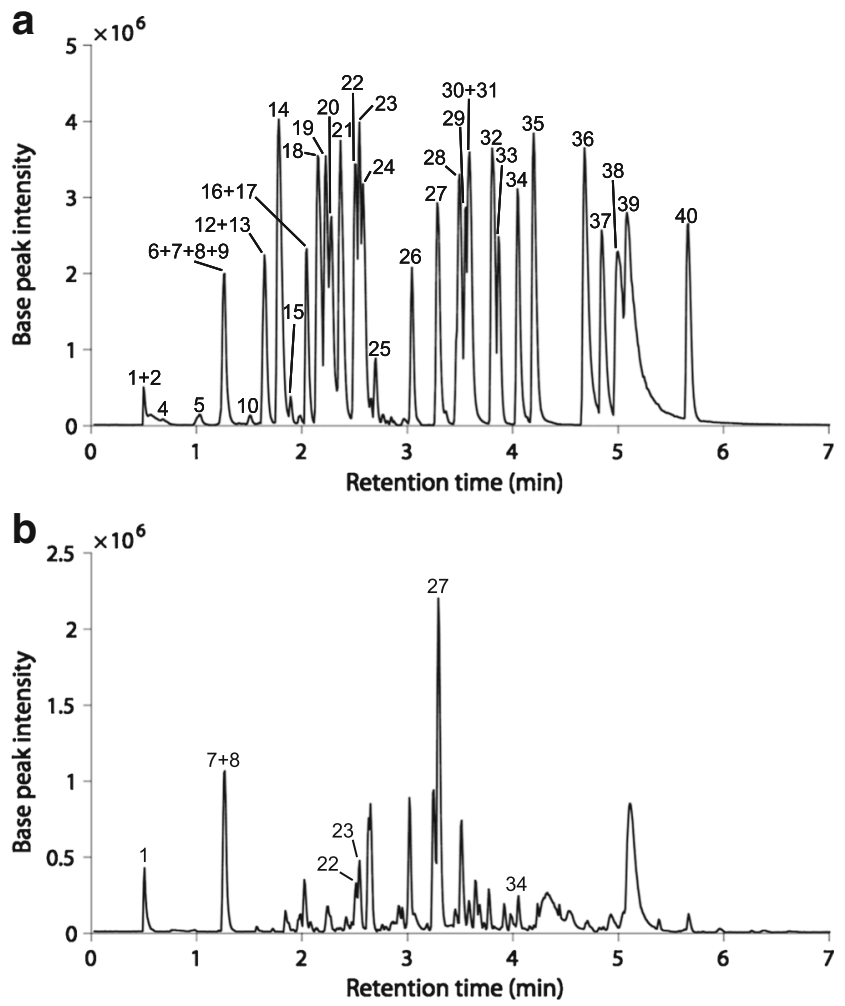

Fig. 4 Obtained base peak ion chromatogram of (a) the multi-standard including 40 lignin-related compounds and (b) lignin sample A, using the optimised UHPSFC/QTOF-MS conditions. For peak identities of the multi-standard, see Table 1. Identified compounds in sample A with the use of the multi-standard are labeled according to the compound number in Table 2

The selectivity of the column was unaffected by the mobile phase flow rate. The best overall separation was achieved at $2 \mathrm{~mL} / \mathrm{min}$, the same flow rate used in the column screening experiment, with lower flow rates causing unnecessarily lengthened analysis time without any obvious improvement in resolution and higher flow rates showing negative effect on resolution (Fig. S3).

As expected, raising the backpressure while keeping other parameters constant generally resulted in weaker retention and shorter analysis time, due to increased elution strength caused by an increase in mobile phase density (ESM Fig. S4). This effect was insignificant for the late-eluting compounds, due to the lower compressibility of the mobile phase containing a large fraction of methanol. Temperature increase at the same backpressure (125 bar) also lowered the mobile phase density, which accordingly increased the retention of the analytes (Fig. S5).

The final method had a column temperature of $50{ }^{\circ} \mathrm{C}$, a backpressure of 130 bar and a flow rate of $2.0 \mathrm{~mL} / \mathrm{min}$. The elution order of all analytes follows the order of polarity in general with acidic analytes being retained the most compared to ketones and aldehydes. Like what was discussed in the column screening part, for compounds with similar structure and polarity, the number of polar moieties and their availability determine the order of elution.

Compared with previously reported HPLC methods of various sets of monomeric lignin model compounds [7, 8, 19], our method greatly shortened the analysis time with a significantly enriched set of compounds. Another advantage shown by the SFC-MS method is the separation of isomeric compounds. Eleven major lignin-derived phenols from alkaline $\mathrm{CuO}$ oxidation were analysed with UHPLC in $15 \mathrm{~min}$ [26]. In our study, a larger set of compounds including the aforementioned 11 phenols was analysed with most of them separated in a shorter time $(6 \mathrm{~min})$. Three lignin monomers in wheat straw were analysed with UHPLC in $3 \mathrm{~min}$ [27] in which the three peaks eluted

Table 3 Obtained results of limit of detection (LOD), limit of quantification (LOQ), linear dynamic range, repeatability and reproducibility of syringaldehyde, 3,4-dimethoxycinnamic acid and sinapyl alcohol from method validation with spiked samples

\begin{tabular}{|c|c|c|c|c|c|c|c|c|}
\hline \multirow{2}{*}{$\begin{array}{l}\text { Lignin } \\
\text { sample }\end{array}$} & \multirow[t]{2}{*}{ Compound spiked } & \multirow{2}{*}{$\begin{array}{l}\text { LOD in } \\
\mu \mathrm{g} / \mathrm{mL}\end{array}$} & \multirow{2}{*}{$\begin{array}{l}\text { LOQ in } \\
\mu \mathrm{g} / \mathrm{mL}\end{array}$} & \multirow{2}{*}{$\begin{array}{l}\text { Dynamic range } \\
\text { in } \mu \mathrm{g} / \mathrm{mL}\end{array}$} & \multicolumn{2}{|c|}{ Repeatability, $\%(\mu \mathrm{g} / \mathrm{mL})$} & \multicolumn{2}{|c|}{ Reproducibility, \% ( $\mu \mathrm{g} / \mathrm{mL})$} \\
\hline & & & & & $\begin{array}{l}\text { RSD near } \\
\text { LOQ }\end{array}$ & $\begin{array}{l}\text { RSD near middle of } \\
\text { dynamic range }\end{array}$ & $\begin{array}{l}\text { RSD near } \\
\text { LOQ }\end{array}$ & $\begin{array}{l}\text { RSD near middle of } \\
\text { dynamic range }\end{array}$ \\
\hline \multirow[t]{3}{*}{ A } & Syringaldehyde & 1.0 & 2.0 & $2.0-1000$ & $5.2(10)$ & $1.6(400)$ & $17.0(10)$ & $11.7(400)$ \\
\hline & $\begin{array}{l}\text { 3,4-Dimethoxycinnamic } \\
\text { acid }\end{array}$ & 0.2 & 1.0 & $1.0-200$ & $2.6(5.0)$ & $1.7(100)$ & $9.1(5.0)$ & $11.3(100)$ \\
\hline & Sinapyl alcohol & 1.0 & 2.0 & $2.0-1000$ & $11.2(10)$ & $1.7(400)$ & $9.2(10)$ & $7.2(400)$ \\
\hline \multirow[t]{3}{*}{ B } & Syringaldehyde & 1.0 & 2.0 & $2.0-1000$ & $3.2(10)$ & $3.5(400)$ & $15.0(10)$ & $15.1(400)$ \\
\hline & $\begin{array}{l}\text { 3,4-Dimethoxycinnamic } \\
\text { acid }\end{array}$ & 0.2 & 1.0 & $1.0-200$ & $3.8(5.0)$ & $1.9(100)$ & $12.2(5.0)$ & $10.0(100)$ \\
\hline & Sinapyl alcohol & 1.0 & 2.0 & $2.0-1000$ & $3.1(10)$ & $2.2(400)$ & $10.3(10)$ & $8.1(400)$ \\
\hline \multirow[t]{3}{*}{$\mathrm{C}$} & Syringaldehyde & 2.0 & 20 & $20-1000$ & $2.2(20)$ & $6.6(400)$ & $18.7(20)$ & $3.5(400)$ \\
\hline & $\begin{array}{l}\text { 3,4-Dimethoxycinnamic } \\
\text { acid }\end{array}$ & 1.0 & 1.5 & $1.5-400$ & $6.6(1.5)$ & $2.7(200)$ & $18.7(1.5)$ & $10.6(200)$ \\
\hline & Sinapyl alcohol & 2.0 & 10 & $10-2000$ & $1.8(10)$ & $1.9(1000)$ & $19.6(10)$ & $16.2(1000)$ \\
\hline
\end{tabular}

RSD: relative standard deviation 
Table 4 Obtained coefficients of determination $\left(R^{2}\right)$ and calibration curve slopes in the dynamic range of syringaldehyde, 3,4-dimethoxycinnamic acid and sinapyl alcohol for spiked samples and standard mixtures

\begin{tabular}{|c|c|c|c|c|c|}
\hline \multirow[t]{2}{*}{ Sample } & \multirow[t]{2}{*}{ Compound spiked } & \multicolumn{2}{|l|}{$R^{2}$} & \multicolumn{2}{|c|}{ Calibration curve slopes } \\
\hline & & Spiked sample & Standard mixture & Spiked sample & Standard mixture \\
\hline \multirow[t]{3}{*}{ A } & Syringaldehyde & 0.9999 & 0.9920 & $50.64 \pm 0.21$ & $92.94 \pm 4.17$ \\
\hline & 3,4-Dimethoxycinnamic acid & 0.9958 & 0.9792 & $291.62 \pm 9.44$ & $291.24 \pm 21.24$ \\
\hline & Sinapyl alcohol & 0.9922 & 0.9987 & $56.30 \pm 2.50$ & $53.87 \pm 0.97$ \\
\hline \multirow[t]{3}{*}{ B } & Syringaldehyde & 0.9985 & 0.9920 & $60.00 \pm 1.15$ & $92.94 \pm 4.17$ \\
\hline & 3,4-Dimethoxycinnamic acid & 0.9950 & 0.9792 & $303.91 \pm 10.83$ & $291.24 \pm 21.24$ \\
\hline & Sinapyl alcohol & 0.9986 & 0.9987 & $65.38 \pm 1.24$ & $53.87 \pm 0.97$ \\
\hline \multirow[t]{3}{*}{$\mathrm{C}$} & Syringaldehyde & 0.9971 & 0.9926 & $18.92 \pm 0.73$ & $90.84 \pm 5.55$ \\
\hline & 3,4-Dimethoxycinnamic acid & 0.9866 & 0.9726 & $214.47 \pm 11.20$ & $320.87 \pm 24.09$ \\
\hline & Sinapyl alcohol & 0.9999 & 0.9740 & $36.09 \pm 0.15$ & $40.98 \pm 3.35$ \\
\hline
\end{tabular}

close to each other between 2.4 and 2.9 min. In comparison, our method had longer analysis time but separating more compounds. Also, the peaks were well scattered among the whole elution range.

\section{Mass spectrometry method optimisation}

To optimise the MS ionisation efficiency, the influence of two qualitative and seven quantitative variables was investigated using a D-optimal design using the number of peaks detected as response. The optimised model showed a total explained variance of $93 \%\left[R^{2}(Y)=0.93\right]$ and a cross-validated predictability of $89 \%\left[Q^{2}(Y)=0.89\right]$. The normalised influence of all significant variables and variable interactions is shown in Fig. 3. The correlation between the predicted number of detected peaks versus the observed number of detected peaks is shown in Fig. S6 (see ESM). The predicted versus experimental data were analysed by linear regression. The experimental and predicted values are highly correlated $(p<0.001)$ and did not differ from the ideal line with a slope of one. From the investigated makeup solvents and makeup solvent additives, only methanol and ammonia respectively showed a positive influence on the response. Therefore, the combination of methanol and ammonia was determined to be the optimal solventadditive combination. Isopropanol and formic acid showed a negative influence on the response, while ammonium formate showed no significant effect. From the investigated quantitative variables, the desolvation gas temperature showed a significant positive influence and the cone voltage a significant negative influence. The positive influence of the desolvation gas temperature could be explained by a more efficient desolvation process at higher temperatures. The negative influence of the cone voltage most likely resulted from increased fragmentation of the standard compounds at higher cone voltages. The concentration of the makeup solvent additive did not show a significant effect, although it did interact significantly with both cone voltage and desolvation gas temperature. The makeup solvent flow rate, source temperature, desolvation gas flow rate and capillary voltage did not influence the response.

Next, an optimiser function, based on a simplex algorithm with a non-linear desirability function, was used to determine factor settings resulting in the highest number of peaks with a relative MS intensity of $\geq 1.0 E 5$. The optimal response was found with methanol as a makeup solvent, $5 \mathrm{mmol} / \mathrm{L}$ ammonia as a makeup solvent additive, a makeup solvent flow rate of $0.2 \mathrm{~mL} / \mathrm{min}$, a source temperature of $120^{\circ} \mathrm{C}$, a desolvation gas temperature of $600^{\circ} \mathrm{C}$, a desolvation gas flow of $1200 \mathrm{~L} / \mathrm{h}$, a capillary voltage of $3.0 \mathrm{kV}$ and a cone voltage of $20 \mathrm{~V}$.

Finally, the optimised condition was tested, enabling the detection of 36 out of 40 compounds in the multi-standard in a single analysis with a relative base peak intensity $\geq 1.0 E 5$ (Table 2, Fig. 4). Only iso-eugenol (relative base peak intensity 9.5E4), phenol (relative MS intensity 3.1E4) and 3,4dihydroxyphenylacetic acid (relative base peak intensity 9.4E4) were below the base peak intensity threshold. Veratraldehyde could not be detected under these conditions.

Because of the high influence of the cone voltage on the response, the cone voltage $20 \mathrm{~V}$ might not be the optimal value. To investigate the influence of the cone voltage, the concentration of the makeup solvent additive and the desolvation gas temperature in more detail, a second design of experiment has been performed. A quadratic model with a face-centred central composite design (CCF) including 17 runs with three centre points was used. However, the results showed no significant improvement compared to the first design of experiment. The obtained results lead to the conclusion that the optimal value for the cone voltage is close to $20 \mathrm{~V}$. The experimental design and the results of the second design of experiment are shown in the supporting information (see ESM, Tables S2 and S3, Figs. S7 and S8). 
Table 5 Identified compounds in the processed lignin samples

\begin{tabular}{|c|c|c|c|c|c|c|c|}
\hline \multirow[t]{2}{*}{ Sample } & \multirow[t]{2}{*}{ Compound } & \multirow{2}{*}{$\begin{array}{l}\text { Retention time } \\
(\mathrm{min})\end{array}$} & \multirow{2}{*}{$\begin{array}{l}\text { Calculated } \\
m / z\left([\mathrm{M}-\mathrm{H}]^{-}\right)\end{array}$} & \multirow{2}{*}{$\begin{array}{l}\text { Measured } \\
m / z\left([\mathrm{M}-\mathrm{H}]^{-}\right)\end{array}$} & \multirow[t]{2}{*}{ Base peak intensity } & \multicolumn{2}{|c|}{$\mathrm{MS}^{2}$ fragmentation } \\
\hline & & & & & & $\mathrm{MS}^{2}$ transition & Lost fragment \\
\hline \multirow[t]{7}{*}{ A } & Guaiacol & 0.51 & 123.0446 & 123.0446 & $4.3 E 5$ & $123 \rightarrow 108$ & $\mathrm{CH}_{3}$ \\
\hline & Vanillin & 1.27 & 151.0395 & 151.0397 & $5.1 E 5$ & $\begin{array}{l}151 \rightarrow 136 \\
151 \rightarrow 108\end{array}$ & $\begin{array}{l}\mathrm{CH}_{3} \\
\mathrm{CH}_{3}+\mathrm{CO}\end{array}$ \\
\hline & Acetovanillone & 1.27 & 165.0552 & 165.0556 & $1.1 E 6$ & $\begin{array}{l}165 \rightarrow 150 \\
165 \rightarrow 122\end{array}$ & $\begin{array}{l}\mathrm{CH}_{3} \\
\mathrm{CH}_{3}+\mathrm{CO}\end{array}$ \\
\hline & $p$-Hydroxybenzaldehyde & 2.51 & 121.0290 & 121.0293 & $3.3 E 5$ & $121 \rightarrow 92$ & $\mathrm{CHO}$ \\
\hline & $p$-Hydroxyacetophenone & 2.55 & 135.0446 & 135.0445 & $4.8 E 5$ & $\begin{array}{l}135 \rightarrow 120 \\
135 \rightarrow 108\end{array}$ & $\begin{array}{l}\mathrm{CH}_{3} \\
\mathrm{C}_{2} \mathrm{H}_{3}\end{array}$ \\
\hline & Vanillic acid & 3.29 & 167.0345 & 167.0356 & $2.2 E 6$ & $\begin{array}{l}167 \rightarrow 152 \\
167 \rightarrow 123 \\
167 \rightarrow 108\end{array}$ & $\begin{array}{l}\mathrm{CH}_{3} \\
\mathrm{CO}_{2} \\
\mathrm{CH}_{3}+\mathrm{CO}_{2}\end{array}$ \\
\hline & $p$-Hydroxybenzoic acid & 4.05 & 137.0239 & 137.0251 & $2.5 E 5$ & $137 \rightarrow 93$ & $\mathrm{CO}_{2}$ \\
\hline \multirow[t]{5}{*}{ B } & Vanillin & 1.27 & 151.0395 & 151.0399 & $2.3 E 5$ & $\begin{array}{l}151 \rightarrow 136 \\
151 \rightarrow 108\end{array}$ & $\begin{array}{l}\mathrm{CH}_{3} \\
\mathrm{CH}_{3}+\mathrm{CO}\end{array}$ \\
\hline & Acetovanillone & 1.27 & 165.0552 & 165.0563 & $1.7 E 5$ & $\begin{array}{l}165 \rightarrow 150 \\
165 \rightarrow 122\end{array}$ & $\begin{array}{l}\mathrm{CH}_{3} \\
\mathrm{CH}_{3}+\mathrm{CO}\end{array}$ \\
\hline & $p$-Hydroxyacetophenone & 2.55 & 135.0446 & 135.0447 & $1.6 E 5$ & $\begin{array}{l}135 \rightarrow 120 \\
135 \rightarrow 108\end{array}$ & $\begin{array}{l}\mathrm{CH}_{3} \\
\mathrm{C}_{2} \mathrm{H}_{3}\end{array}$ \\
\hline & Vanillic acid & 3.29 & 167.0345 & 167.0349 & $2.3 E 6$ & $\begin{array}{l}167 \rightarrow 152 \\
167 \rightarrow 123 \\
167 \rightarrow 108\end{array}$ & $\begin{array}{l}\mathrm{CH}_{3} \\
\mathrm{CO}_{2} \\
\mathrm{CH}_{3}+\mathrm{CO}_{2}\end{array}$ \\
\hline & $p$-Hydroxybenzoic acid & 4.05 & 137.0239 & 137.0254 & $2.4 E 5$ & $137 \rightarrow 93$ & $\mathrm{CO}_{2}$ \\
\hline \multirow[t]{5}{*}{$\mathrm{C}$} & Guaiacol & 0.50 & 123.0446 & 123.0442 & $1.4 E 6$ & $123 \rightarrow 108$ & $\mathrm{CH}_{3}$ \\
\hline & Vanillin & 1.26 & 151.0395 & 151.0391 & $3.0 E 5$ & $\begin{array}{l}151 \rightarrow 136 \\
151 \rightarrow 108\end{array}$ & $\begin{array}{l}\mathrm{CH}_{3} \\
\mathrm{CH}_{3}+\mathrm{CO}\end{array}$ \\
\hline & Acetovanillone & 1.26 & 165.0552 & 165.0553 & $1.7 E 6$ & $\begin{array}{l}165 \rightarrow 150 \\
165 \rightarrow 122\end{array}$ & $\begin{array}{l}\mathrm{CH}_{3} \\
\mathrm{CH}_{3}+\mathrm{CO}\end{array}$ \\
\hline & $p$-Hydroxybenzaldehyde & 2.49 & 121.0290 & 121.0290 & $1.2 E 5$ & $121 \rightarrow 92$ & $\mathrm{CHO}$ \\
\hline & $p$-Hydroxyacetophenone & 2.53 & 135.0446 & 135.0441 & $8.2 E 5$ & $\begin{array}{l}135 \rightarrow 120 \\
135 \rightarrow 108\end{array}$ & $\begin{array}{l}\mathrm{CH}_{3} \\
\mathrm{C}_{2} \mathrm{H}_{3}\end{array}$ \\
\hline \multirow[t]{4}{*}{$\mathrm{D}$} & Sinapaldehyde & 2.14 & 207.0658 & 207.0645 & $1.6 E 4$ & $\begin{array}{l}207 \rightarrow 192 \\
207 \rightarrow 177\end{array}$ & $\begin{array}{l}\mathrm{CH}_{3} \\
2 \times \mathrm{CH}_{3}\end{array}$ \\
\hline & Syringic acid & 3.50 & 197.0450 & 197.0446 & $3.4 E 6$ & $\begin{array}{l}197 \rightarrow 123 \\
197 \rightarrow 95\end{array}$ & $\begin{array}{l}2 \times \mathrm{CH}_{3}+\mathrm{CO}_{2} \\
2 \times \mathrm{CH}_{3}+\mathrm{CO}_{2}+\mathrm{CO}\end{array}$ \\
\hline & Ferulic acid & 3.60 & 193.0501 & 193.0490 & $1.5 E 4$ & $193 \rightarrow 134$ & $\mathrm{CH}_{3}+\mathrm{CO}_{2}$ \\
\hline & Sinapinic acid & 3.81 & 223.0607 & 223.0603 & $3.7 E 6$ & $\begin{array}{l}223 \rightarrow 193 \\
223 \rightarrow 149 \\
223 \rightarrow 121\end{array}$ & $\begin{array}{l}2 \times \mathrm{CH}_{3} \\
2 \times \mathrm{CH}_{3}+\mathrm{CO}_{2} \\
2 \times \mathrm{CH}_{3}+\mathrm{CO}_{2} \\
+2 \times \mathrm{CH}_{2}\end{array}$ \\
\hline
\end{tabular}

\section{Method validation}

LOD, LOQ, dynamic range and within-day and inter-day precision of peak area for the three compounds (syringaldehyde, 3,4-dimethoxycinnamic acid and sinapyl alcohol) in lignin samples $\mathrm{A}, \mathrm{B}$ and $\mathrm{C}$ are shown in Table 3. The higher LOD and LOQ observed in the $\mathrm{C}$ sample can be attributed to its greater complexity as compared with the other two samples, causing increased matrix interference and ionisation suppression.
The impact of sample matrix effects on target analyte signal intensity was evaluated by comparing the slopes of calibration curves derived from pure standards and from spiked samples [28]. As can be calculated from the results shown in Table 4, syringaldehyde showed a $46 \%$ decrease in sample A. Calibration curve slopes for 3,4-dimethoxycinnamic acid and sinapyl alcohol in sample A were not impacted by the matrix. In B samples, the calibration curve slope for sinapyl alcohol was unaltered, whereas the slopes were 36 and $17 \%$ lower for syringaldehyde and 3,4-dimethoxycinnamic acid, 
respectively, and the calibration curve slope decreased for all spiked compounds in sample C $(80 \%$ for syringaldehyde, $42 \%$ for 3,4-dimethoxycinnamic acid and $12 \%$ for sinapyl alcohol). Hence, the greater complexity of the $\mathrm{C}$ sample also led to a more pronounced ionisation suppression. As a consequence of these matrix effects, the quantitative analysis based on the calibration obtained with pure standards is rendered unreliable.

The MS ionisation efficiency can be compared using the achieved LODs. Owen et al. achieved for similar ligninrelated monomers lower LODs compared to this study by using reversed-phase LC coupled to a linear ion trap/Fourier transform ion cyclotron resonance MS (vanillin $4.0 \times 10^{-3} \mu \mathrm{g} / \mathrm{mL}$; 2-methoxy-4-propylphenol $3.0 \times 10^{-3} \mu \mathrm{g} / \mathrm{mL}$ ) [8]. Also, Zheng et al. achieved lower LODs by using reversed-phase LC coupled to a triple-quadrupole MS ( $p$-hydroxybenzaldehyde $4.0 \times 10^{-4} \mu \mathrm{g} / \mathrm{mL}$; vanillin $2.1 \times 10^{-4} \mu \mathrm{g} / \mathrm{mL}$; syringaldehyde $8.9 \times 10^{-4} \mu \mathrm{g} / \mathrm{mL}$ ) [27]. A possible reason might be that the LODs determined in this study (Table 3 ) have been determined by using spiked lignin samples instead of solvent standards like in the studies of Owen et al. and Zhang et al. Using spiked lignin samples gives ion suppression effects and negative effects on the LOD. The use of different mass analysers also explains the deviating LODs.

\section{Analysis of processed lignin samples}

A qualitative analysis of the processed lignin samples was performed with the optimised UHPSFC/QTOF-MS method (see Table 5). Several lignin-derived monomeric compounds could be identified. A base peak ion chromatogram of sample A is shown in Fig. 4. The base peak ion chromatograms of samples B, C and D are shown in Fig. S9 (see ESM). In samples $\mathrm{A}, \mathrm{B}$ and $\mathrm{C}$, vanillin, acetovanillone and $p$ hydroxyacetophenone could be identified. Guaiacol and $p$ hydroxybenzaldehyde could be identified in sample A as well as in sample $\mathrm{C}$, and vanillic acid and $p$-hydroxybenzoic acid could be identified in sample A and sample B. In sample D, sinapaldehyde, syringic acid, ferulic acid and sinapinic acid could be identified. The base peak ion chromatogram of all lignin samples shows that the samples are complex mixtures and include more compounds than the identified ones. Further work is required to identify these unknown peaks.

\section{Conclusions}

An UHPSFC/QTOF-MS method for the analysis of ligninderived monomeric compounds from processed lignin samples was developed in this work. Thirty-two of the 40 compounds are partially or baseline separated in less than $6 \mathrm{~min}$. Column screening results showed that the bonding technology and functionalisation of chromatographic particles contribute to a significant improvement in resolving power. Enhanced $\pi-\pi$ interaction is needed to separate the early eluting lignin phenols with similar structures. Hydrogen bonding interaction can be effectively harnessed to separate lignin-derived compounds. However, ion-ion interaction is not appreciated as it lengthens the retention time of phenolic acids to an unnecessary extent. With the optimised MS method, 36 of 40 compounds could be detected with a relative MS intensity of $\geq$ $1.0 E 5$. The cone voltage and the desolvation temperature were found to have the strongest impact of all investigated ion source parameters on ionisation efficiency. Finally, the applicability of the method for qualitative and quantitative analysis of processed lignin samples was demonstrated. Clearly, UHPSFC-MS has its benefits in comparison to UHPLC-MS in terms of selectivity and speed.

Acknowledgements The authors would like to thank the Swedish Research Council Formas (2013-971, 2016-00604) and the Swedish Foundation for Strategic Research (SSF, RBP 14-0052) for the financial support. We thank Christian Hulteberg, Gunnar Lidén, Javier Garcia Hidalgo and Omar Y. Abdelaziz (Lund University, Lund, Sweden) and Joseph Samec and Maxim Gulkin (Stockholm University, Stockholm, Sweden) for kindly providing the processed lignin samples. We are grateful to Sofia Essén for the help in MS analysis.

\section{Compliance with ethical standards}

Conflict of interest The authors declare that they have no conflict of interest.

Open Access This article is distributed under the terms of the Creative Commons Attribution 4.0 International License (http:// creativecommons.org/licenses/by/4.0/), which permits unrestricted use, distribution, and reproduction in any medium, provided you give appropriate credit to the original author(s) and the source, provide a link to the Creative Commons license, and indicate if changes were made.

\section{References}

1. Vanholme R, Demedts B, Morreel K, Ralph J, Boerjan W. Lignin biosynthesis and structure. Plant Physiol. 2010;153(3):895-905. https://doi.org/10.1104/pp.110.155119.

2. Abdelaziz OY, Brink DP, Prothmann J, Ravi K, Sun MZ, GarciaHidalgo J, et al. Biological valorization of low molecular weight lignin. Biotechnol Adv. 2016;34(8):1318-46. https://doi.org/10 1016/j.biotechadv.2016.10.001.

3. Thring RW, Chornet E, Overend RP. Analysis of phenols from lignin depolymerization by capillary gas-chromatography. J Chromatogr. 1989;467(2):441-6. https://doi.org/10.1016/S00219673(01)93999-8.

4. Xu WY, Miller SJ, Agrawal PK, Jones CW. Depolymerization and hydrodeoxygenation of switchgrass lignin with formic acid. ChemSusChem. 2012;5(4):667-75. https://doi.org/10.1002/cssc. 201100695.

5. Louchouarn P, Amon RMW, Duan SW, Pondell C, Seward SM, White N. Analysis of lignin-derived phenols in standard reference materials and ocean dissolved organic matter by gas chromatography/tandem mass spectrometry. Mar Chem. 
2010;118(1-2):85-97. https://doi.org/10.1016/j.marchem.2009.11. 003.

6. Orata F. Derivatization reactions and reagents for gas chromatography analysis. In: Mohd MA, editor. Advanced gas chromatography - progress in agricultural, biomedical and industrial applications. Rijeka: InTech; 2012. p. 84-108.

7. Jarrell TM, Marcum CL, Sheng HM, Owen BC, O’Lenick CJ, Maraun $\mathrm{H}$, et al. Characterization of organosolv switchgrass lignin by using high performance liquid chromatography/ high resolution tandem mass spectrometry using hydroxide-doped negative-ion mode electrospray ionization. Green Chem. 2014;16(5):2713-27. https://doi.org/10.1039/c3gc42355g.

8. Owen BC, Haupert LJ, Jarrell TM, Marcum CL, Parsell TH, AbuOmar MM, et al. High-performance liquid chromatography/highresolution multiple stage tandem mass spectrometry using negativeion-mode hydroxide-doped electrospray ionization for the characterization of lignin degradation products. Anal Chem. 2012;84(14): 6000-7. https://doi.org/10.1021/ac300762y.

9. Haupert LJ, Owen BC, Marcum CL, Jarrell TM, Pulliam CJ, Amundson LM, et al. Characterization of model compounds of processed lignin and the lignome by using atmospheric pressure ionization tandem mass spectrometry. Fuel. 2012;95(1):634-41. https://doi.org/10.1016/j.fuel.2011.12.015.

10. Guiochon G, Tarafder A. Fundamental challenges and opportunities for preparative supercritical fluid chromatography. J Chromatogr A. 2011;1218(8):1037-114. https://doi.org/10.1016/j. chroma.2010.12.047.

11. Novakova L, Grand-Guillaume Perrenoud A, Francois I, West C, Lesellier E, Guillarme D. Modern analytical supercritical fluid chromatography using columns packed with sub- $2 \mu \mathrm{m}$ particles: a tutorial. Anal Chim Acta. 2014;824:18-35. https://doi.org/10.1016/j. aca.2014.03.034.

12. Lesellier E. Retention mechanisms in super/subcritical fluid chromatography on packed columns. J Chromatogr A. 2009;1216(10): 1881-90. https://doi.org/10.1016/j.chroma.2008.10.081.

13. West $\mathrm{C}$, Lesellier $\mathrm{E}$. A unified classification of stationary phases for packed column supercritical fluid chromatography. J Chromatogr A. 2008;1191(1-2):21-39. https://doi.org/10.1016/j.chroma.2008. 02.108 .

14. Lemasson E, Bertin S, West C. Use and practice of achiral and chiral supercritical fluid chromatography in pharmaceutical analysis and purification. J Sep Sci. 2016;39(1):212-33. https://doi.org/ 10.1002/jssc.201501062.

15. Ganzera M. Supercritical fluid chromatography for the separation of isoflavones. J Pharmaceut Biomed. 2015;107:364-9. https://doi. org/10.1016/j.jpba.2015.01.013.

16. Ramirez P, Senorans FJ, Ibanez E, Reglero G. Separation of rosemary antioxidant compounds by supercritical fluid chromatography on coated packed capillary columns. J Chromatogr A. 2004;1057(1-2):241-5. https://doi.org/10.1016/j.chroma.2004.09. 037.
17. Kamangerpour A, Ashraf-Khorassani M, Taylor LT, McNair HM, Chorida L. Supercritical fluid chromatography of polyphenolic compounds in grape seed extract. Chromatographia. 2002;55(78):417-21. https://doi.org/10.1007/Bf02492270.

18. Sun MZ, Liden G, Sandahl M, Turner C. Ultra-high performance supercritical fluid chromatography of lignin-derived phenols from alkaline cupric oxide oxidation. J Sep Sci. 2016;39(16):3123-9. https://doi.org/10.1002/jssc.201600169.

19. Lobbes JM, Fitznar HP, Kattner G. High-performance liquid chromatography of lignin-derived phenols in environmental samples with diode array detection. Anal Chem. 1999;71(15):3008-12. https://doi.org/10.1021/ac981175i.

20. Novakova L, Grand-Guillaume Perrenoud A, Nicoli R, Saugy M, Veuthey JL, Guillarme D. Ultra high performance supercritical fluid chromatography coupled with tandem mass spectrometry for screening of doping agents. I: investigation of mobile phase and MS conditions. Anal Chim Acta. 2015;853:637-46. https://doi. org/10.1016/j.aca.2014.10.004.

21. Li FB, Hsieh YS. Supercritical fluid chromatography-mass spectrometry for chemical analysis. J Sep Sci. 2008;31(8):1231-7. https://doi.org/10.1002/jssc.200700581.

22. Grand-Guillaume Perrenoud A, Veuthey JL, Guillarme D. Coupling state-of-the-art supercritical fluid chromatography and mass spectrometry: from hyphenation interface optimization to high-sensitivity analysis of pharmaceutical compounds. J Chromatogr A. 2014;1339:174-84. https://doi.org/10.1016/j. chroma.2014.03.006.

23. Berger TA, Deye JF. Role of additives in packed-column supercritical fluid chromatography: suppression of solute ionization. J Chromatogr. 1991;547(1-2):377-92. https://doi.org/10.1016/ S0021-9673(01)88661-1.

24. West C, Melin J, Ansouri H, Metogo MM. Unravelling the effects of mobile phase additives in supercritical fluid chromatography. Part I: polarity and acidity of the mobile phase. J Chromatogr A. 2017;1492:136-43. https://doi.org/10.1016/j.chroma.2017.02.066.

25. Strubinger JR, Song HC, Parcher JF. High-pressure phase distribution isotherms for supercritical fluid chromatographic systems. 1. Pure carbon dioxide. Anal Chem. 1991;63(2):98-103. https://doi. org/10.1021/ac00002a003.

26. Ouyang XP, Chen ZL, Qiu XQ. Determination of monophenolic compounds from lignin oxidative degradation using ultra performance liquid chromatography/high resolution mass spectrometry. Chin J Anal Chem. 2014;42(5):723-8. https://doi.org/10.3724/Sp. J.1096.2014.31142.

27. Zheng M, Gu S, Chen J, Luo Y, Li W, Ni J, et al. Development and validation of a sensitive UPLC-MS/MS instrumentation and alkaline nitrobenzene oxidation method for the determination of lignin monomers in wheat straw. J Chromatogr B. 2017;1055-1056:17884.

28. Ellison SLR, Thompson M. Standard additions: myth and reality. Analyst. 2008;133(8):992-7. https://doi.org/10.1039/b717660k. 